УДК 33

DOI $10.21661 / \mathrm{r}-463824$

\title{
В.А. Елисеев
}

\section{ЭТАПНЫЕ ПЕРСПЕКТИВЫ РАЗВИТИЯ ЖЕЛЕЗНОДОРОЖНОЙ ЭНЕРГЕТИКИ}

Аннотация: в аналитическом рассмотрении этапной Энергетической стратегии Холдинга «РЖД» изложены целевые показатели его деятельности и приведены задачи энергетической политики. На обозначенных этапах реализации стратегии отмечены установленные приоритеты, ориентиры и механизмы развития. Показано отношение стратегии крегламентирующим государственнымм нормативным актам и документам, а отечественной ж. -д. энергетики энергосбережению и повышению энергетической эффективности страны.

Ключевые слова: железнодорожный транспорт, энергетическая стратегия, Холдинг «РЖД».

\section{V.A. Yeliseyev}

\section{GRADUAL PROSPECTS OF DEVELOPMENT OF RAILWAY ENERGY}

Abstract: in the analytical review of the Energy Strategy of the RZD Holding, the target indicators of its activities are set out and the tasks of the energy policy are listed. At the identified stages of the strategy implementation, the identified priorities, benchmarks and development mechanisms were noted. The relation of the strategy to the regulatory state regulations and documents, also the relation of the domestic railroad train energy to saving energy and improving the country's energy efficiency are shown.

Keywords: railway transport, energy strategy, RZD Holding.

Общие положения Энергетической стратегии и текущฺе результаты ее реализащии. В соответствии со «Стратегией развития ж.-д. транспорта в РФ до 2030 г.» [1] ОАО «РЖД» разработана и утверждена Энергетическая стратегия 
ОАО/Холдинга «РЖД», основанная на регламентирующих политику государства в области энергетики и энергосбережения нормативных актах и документах. Энергетическая стратегия:

- является составной частью «Комплексной программы инновационного развития холдинга на 2016-2020 годы» [2], поэтапно, но не реже чем раз в 5 лет, пересматривается и уточняется [3-5];

- обосновывает необходимость актуализации энергетической стратегии Холдинга на перспективу до 2030 г.;

- устанавливает целевые показатели в области энергосбережения и повышения энергетической эффективности для филиалов ОАО «РЖД» и подведомственных структурных подразделений;

- определяет задачи энергетической политики Холдинга и его бизнес-блоков на средне- и долгосрочный периоды развития, приоритеты, ориентиры и механизмы на этапах реализации;

- обеспечивает разработку и утверждение последующей программы реализации.

Для максимально рационального использования энергетических ресурсов, дальнейшей минимизации негативного воздействия ж.-д. транспорта на окружающую среду и поддержания лидерских позиций Холдинга в области энергоэффективности ж.-д. грузо- и пассажирских перевозок среди транспортных компаний мира Энергетическая стратегия (с вытекающими приоритетными задачами) ориентируется на повышение технологического уровня бизнес-блоков Холдинга.

Механизм разработки актуализированной Энергетической стратегии заключается в системном (комплексном) анализе состояния развития Холдинга в энергетической сфере, внешней и внутренней среды, определении целевых энергетических показателей на конец стратегического горизонта планирования, а также инструментов по их достижению. Учитывались характеристики макро(PEST-анализ), микро- и внутренней среды Холдинга, а в качестве инструмента, 
связывающего анализ внешней и внутренней среды со стратегическими альтернативами Энергетической стратегии Холдингом выбрана техника SWOTанализа. Результатом разработки стратегии явилось построение стратегической карты, отражающей прогноз развития Холдинга с учетом возможных сценариев.

Механизм реализации Энергетической стратегии Холдинга предполагается за счет текущих затрат функциональных филиалов ОАО «РЖД», через целевые инвестиционные проекты и программы, направленные на повышение надежности и эффективности энергообеспечения производственных процессов, а также через организационные мероприятия в бизнес-блоках Холдинга по совершенствованию системы управления энергопотреблением, по энергосбережению и повышению энергетической эффективности. Учитывая капиталоемкость основных энергетических фондов инфраструктуры Холдинга и длительные сроки окупаемости инвестиций, предпочтительными источниками финансирования обновления и развития объектов инфраструктуры тяговой энергетики должны стать государственные инвестиции, прибыль и инвестиционная составляющая тарифов на услуги по передаче (транзиту) электроэнергии.

Несмотря имеющееся снижение темпов роста перевозок, в качестве текущзего результата реализациии Энергетической стратегии, наблюдается значительное снижение удельного расхода энергоресурсов в обоих видах тяги (по электроэнергии и дизельному топливу). Кроме эксплуатационных показателей значительный вклад в снижение удельного расхода электроэнергии на тягу поездов вносит повышение эффективности применения рекуперативного торможения, а основными причинами, обеспечивающими рост объема рекуперации, являются: электрификация отдельных участков со сложным профилем пути; восстановление более 600 систем рекуперативного торможения; обновление парка электроподвижного состава, более эффективно реализующего рекуперативное торможение; внедрение выпрямительно-инверторных преобразователей нового поколения на тяговых подстанциях постоянного тока; усиление контроля применения рекуперативного торможения; пересмотр нормативных документов и режимных карт в части применения рекуперативного торможения. В соответствии 
с Федеральным законом [6] ФСТ России ежегодно устанавливает для ОАО «РЖД» и АО «Федеральная пассажирская компания» целевые показатели энергосбережения и повышения энергетической эффективности, а также их значения, достижение которых должно быть обеспечено в ходе реализации программ в области энергосбережения и повышения энергетической эффективности.

Цель статьи - путем аналитического рассмотрения в сжатой форме изложить очередную этапную Энергетическую стратегии Холдинга «РЖД», отметив целевые показатели и приведя задачи его энергетической политики, установленные приоритеты, ориентиры и механизмы развития.

Развитие энергетического комплекса Холдинга. Анализ внешней макроcpeдbl развития Холдинга свидетельствуют об устойчивой тенденции развития отраслей топливно-энергетического комплекса страны в перспективе до 2030 г. и показывает, что Холдинг не должен испытывать проблем с дефицитом топливно-энергетических ресурсов при закупке на внутреннем рынке. Кроме того, анализ угроз и возможностей развития топливно-энергетического комплекса определил основные направления парирующих мероприятий Холдинга, а именно:

- интенсификация потребления сжиженного природного газа как газомоторного топлива в автономной тяге и возможность перевода на газ теплоснабжающих и теплопотребляющих объектов ж.-д. транспорта;

- ускоренное развитие возобновляемых источников энергии, развитие нетопливной энергетики;

- развитие «умных» (smart) энергетических технологий;

- создание системы координации региональных программ развития экономики и энергетики в соответствии с Энергетической стратегией;

- мониторинг энергетического рынка (в области развития энергетических технологий и оборудования, энергетической информации, научно-технических разработок, законодательства, нормативов, стандартов и технических правил); 
- для сокращения сроков реализации инноваций участие в работе отраслевых инновационных центров, экспертных групп, научных кластерах;

- опережающая организация кадрового обеспечения разработки, внедрения и эксплуатации новых энерготехнологий на ж.-д. транспорте.

Анализ внешней микросреды развития Холдинга показывает, что среди ж.-д. компаний он остается в числе мировых лидеров по энергоэффективности и экологичности грузовых и пассажирских перевозок. Хотя по данным Международного энергетического агентства, в отдельных странах улучшение результативности энергосберегающей деятельности происходит намного быстрее, чем в РФ; это можно объяснить тем, что потенциал снижения энергоемкости отечественных железных дорог во многом уже использован (достигнут естественный предел эффективности имеющихся технологий), а дальнейшее снижение возможно за счет внедрения инновационных, наукоемких и затратных, но энергоэффективных технических средств и технологий.

Анализ внутренней среды развития Холдинга показывает, во-первых, что установлено увеличение потенциальных возможностей электросетевого хозяйства по технологическому присоединению потребителей и по объему оказываемых услуг в передаче электроэнергии по сетям Холдинга. А во-вторых, наблюдается связь с объявленной в Энергетической стратегии необходимостью обеспечения эффективности производственных процессов, направленных на рациональное использование всех видов ресурсов, и снижение воздействия на окружающую среду; при этом ключевым фактором обозначено формирование модели по пяти бизнес-блокам Холдинга с разработкой целевых показателей по каждому из блоков и Холдингу в целом (к основным блокам, направления развития и стратегические инициативы которых будут оказывать существенное влияние на уровень эффективности использования топливно-энергетических ресурсов, относятся транспортно-логистический, ж.-д. перевозок и инфраструктуры, пассажирских перевозок). 
Организационно-техническое обеспечение реализаџии Энергетической стратегии Холдинга связано с урегулированием противоречий в части потребления топливно-энергетических ресурсов, с корректностью определения расходов соответствующими структурами (Дирекция тяги, Центральная дирекция инфраструктуры и проч.). Функции обеспечения баланса экономических интересов возложены на Управление планирования и нормирования материально-технических ресурсов ОАО «РЖД» и Топливно-энергетических центров железных дорог, а функции организации деятельности по повышению энергетической эффективности возложены на Департамент технической политики ОАО. Требования к системе управления энергоэффективностью производственных процессов ОАО установлены СТО РЖД [7]. Кроме того, в развитие автоматизации системы энергоменеджмента создается единая АСУ топливно-энергетическими ресурсами ОАО.

Для снижения возможных потерь в качестве ориентиров развития энергетического комплекса Холдинга в практике его деятельности используются принципы диверсификации на основе подходов риск-менеджмента. В рамках карты рисков оценены уровни вероятности их возникновения и воздействие которых может оказать влияние на энергетическую сферу. Анализ направлений развития энергетики и конъюнктуры рынка транспортно-логистических услуг проводился сопоставлением сильных и слабых сторон внутренней среды Холдинга с возможностями и угрозами среды внешней; при этом SWOT-анализ показывает вероятность возникновения определенных внутренних и внешних вызовов (рисков) в границах горизонта планирования энергетического обеспечения. Для снижения или полного устранения угроз/рисков разработаны соответствующие меры в части преодоления:

- изменения спроса на транспортные услуги (на объем перевозок);

- усиления конкуренции на рынке транспортных услуг при повышении требований клиентов к качеству услуг;

- эксплуатационных рисков, которые могут привести к снижению показателей энергоэффективности; 
- зависимости Холдинга от импорта запчастей и компонентов;

- финансовых рисков (в т. ч. опережающего роста тарифов на энергоресурсы по сравнению с тарифами на перевозки);

- сложности тиражирования проектов и мероприятий в области энергосбережения в совокупности с недостаточно эффективной нормативно-технической базой и возможным снижением финансирования;

- сложности оценки и прогнозирования производственных показателей Холдинга (в т. ч. показателей его энергоэффективности, зависящих от требований федерального законодательства по электроэнергетике) вплоть до перераспределения потоков финансирования инвестиционных программ развития, ремонта и технического обслуживания, программ энергосбережения и даже до потери Холдингом электросетевого бизнеса.

Векторы развития и потенциал повышения энергоэффективности Холдинга. Направления развития перевозочного процесса связаны с повышением его энергоэффективности и энергобезопасности. К основным технико-технологическим решениям, на которые ориентируется энергетика Холдинга в области повышения эффективности перевозочного процесса, относятся:

- разработка и внедрение энергетически эффективного тягового подвижного состава, модернизация существующего локомотивного парка;

- повышение эффективности моторвагонного подвижного состава;

- обновление парка грузовых и пассажирских вагонов;

- совершенствование принципов организации и управления перевозочным процессом.

К направлениям стратегии развития энергетического комплекса Холдинга отнесены:

1) развитие электросетевого комплекса (с вариантами развития услуг по передаче электроэнергии по сетям Холдинга и приоритетными мероприятиями по развитию электросетевого комплекса в рамках инвестиционных проектов «Об- 
новление оборудования и устройств электроснабжения» и «Внедрение ресурсосберегающих технологий на ж.-д. транспорте», а также по организации учета электроэнергии);

2) развитие комплекса тепловодоснабжения и водоотведения. Отдельно выделены, во-первых, направления стратегии развития инфраструктурного комплекса, нетяговой энергетики (повышение ее эффективности), систем энергообеспечения зданий и сооружений, а во-вторых, развитие систем управления процессами потребления энергоресурсов (в т. ч. улучшение структуры управления энергетическим комплексом Холдинга) и обеспечения эффективной деятельности в области энергосбережения.

Прогноз развития Холдинга в области энергосбережения и повышения энергоэффективности. В соответствии со сценариями социально-экономического развития РФ в долгосрочной перспективе (консервативный, инновационный и целевой / форсированный) [8] Холдингом сформировано вариантьл (сценарии) реализацчии Энергетической стратегии на период до 2030 г.: консервативный (пессимистичный), базовый и оптимистичный (инновационный). Консервативный (пессимистичный) вариант основывается на консервативном сценарии долгосрочного прогноза социально-экономического развития и предусматривает инерционное развитие Холдинга без существенного роста инвестиций в развитие. Базовый вариант также основывается на консервативном сценарии долгосрочного прогноза, но предусматривает минимально необходимое развитие инфраструктуры для удовлетворения спроса на перевозки при условии увеличения мер господдержки. Оптимистичный вариант основывается на инновационном сценарии долгосрочного прогноза социально-экономического развития РФ и предусматривает полное удовлетворение Холдингом спроса на перевозки. На основе этих вариантов стратегии Холдингом разработан прогноз изменения объемов перевозочной работы на электрической и дизельной тяге, который предусматривает увеличение доли перевозочной работы на электротяге. 
Ожидаемье результатьл реализаџии вариантов Энергетической стратегии следующие. На базе сценарных показателей перевозочного процесса и анализа имеющегося потенциала энергосбережения технических средств и технологий определены прогнозируемые перспективы значения удельного расхода топливно-энергетических ресурсов на тягу поездов для каждого вида тяги. На основе анализа приоритетных направлений развития Холдинга в области энергосбережения и повышения энергоэффективности, а также основных инструментов (механизмов) развития энергетического хозяйства, сформированы ключевые целевые показатели (ключевые показатели эффективности) Холдинга, основные принципы формирования системы которых определяются Методическими указаниями Минэкономразвития России [9]. Определена динамика снижения энергоемкости производственной деятельности ОАО «РЖД» - интегрального индикатора действенности мер по энергосбережению и повышению энергетической эффективности, изменения структуры энергобаланса и совершенствования системы управления приобретением и потреблением топливно-энергетических ресурсов. С учетом ожидаемых результатов реализации стратегии сформирован прогноз потребности Холдинга в топливно-энергетических ресурсах по всем сценариям, демонстрирующий увеличение доли электропотребления на тягу поездов в общем энергетическом балансе.

Мониторинг и верификаџия результатов реализаџии стратегии. Мониторинг эффективности программы мероприятий реализации стратегии и верификация результатов этих мероприятий «отсеивают» пилотные проекты (которые в процессе эксплуатации не дали ожидаемого эффекта), организационно и технологически корректируют процесс дальнейшей реализации стратегии, в т. ч. в соответствии с контролируемыми государством целевыми показателями энергетической эффективности производственной деятельности ОАО «РЖД» [6]. Мониторинг результатов реализации проводится на базе системы энергоменеджмента, отвечающей стандартизованным требованиям [10] - составной части общей системы управления ОАО. Кроме того, разработана Стратегическая карта развития 
Холдинга по управлению процессами потребления энергоресурсов и обеспечению эффективной деятельности в области энергосбережения (в виде матрицы SWOT-анализа Холдинга в области энергетического развития).

\section{Заключение}

На фоне известных рисков и угроз, связанных с внутренними ограничениями и госрегулированием, в анализируемой актуализированной Энергетической стратегии Холдинга «РЖД» отсутствует направленно-отраслевое сравнение с прогнозируемым уровнем зарубежного инновационного развития ж.-д. энергетики - это касается установленных целевых показателей Холдинга в области энергосбережения и повышения энергетической эффективности, а также вытекающих задач его энергетической политики, приоритетов, ориентиров и механизмов на обозначенных этапах реализации стратегии. Однако Энергетическая стратегия предполагает и обеспечивает разработку и утверждение последующей Программы ее реализации, в рамках которой, можно предположить, будет проведен соответствующий сравнительный анализ.

\section{Сиисок литературы}

1. Распоряжение Правительства РФ от 17 июня 2008 года №877-р «О Стратегии развития железнодорожного транспорта в Российской Федерации до 2030 года».

2. «Комплексная программа инновационного развития холдинга на 2016-2020 годы», одобренная Правлением ОАО «РЖД» на заседании 31 марта 2016 года.

3. Распоряжение ОАО «РЖД от 11 февраля 2008 года №269p «Энергетическая стратегия ОАО «РЖД» на период до 2010 года и на перспективу до 2030 года».

4. Распоряжение ОАО «РЖД от 15 декабря 2011 года №2718р «Энергетическая стратегия холдинга «Российские железные дороги» на период до 2015 года и на перспективу до 2030 года». 
5. Распоряжение ОАО «РЖД от 14 декабря 2016 года №2537p «Об утверждении энергетической стратегии холдинга «Российские железные дороги» на период до 2020 года и на перспективу до 2030 года».

6. Федеральный закон «Об энергосбережении и о повышении энергетической эффективности и о внесении изменений в отдельные законодательные акты Российской Федерации» от 23 ноября 2009 года №261-Ф3.

7. Стандарт ОАО «РЖД» СТО РЖД 08.017-2012. «Система управления энергоэффективностью производственных процессов. Основные положения». Утвержден Распоряжением ОАО «РЖД» от 24 декабря 2012 года №2674p.

8. Прогноз долгосрочного социально-экономического развития Российской Федерации на период до 2030 года. Минэкономразвития России. 25 марта 2013 года.

9. Методические указания по ежегодной оценке реализации программ инновационного развития акционерных обществ с государственным участием, государственных корпораций и федеральных государственных унитарных предприятий. Минэкономразвития России. 3 июля 2015 года.

10. ГОСТ Р ИСО 50001-2014. Системы энергетического менеджмента. Требования и руководство по применению.

Елисеев Владимир Алексеевич - д-р техн. наук, профессор, главный научный сотрудник $3 \mathrm{AO}$ «Институт инновационно-технологического менеджмента», Россия, Москва.

Yeliseyev Vladimir Alekseevich - doctor of engineering sciences, professor, chief research officer of CJSC «Institute for Technology Innovation Management», Russia, Moscow. 